\title{
Modern Nanotechnology Application for Generation Highly Efficient Electricity in Save Mode and Much Less Polluting
}

\author{
Mohammed Flayyih HASAN ${ }^{1, *}$, Merdin DANISMAZ ${ }^{2}$, Faez WAHEED ${ }^{3}$ \\ ${ }^{1}$ Kirsehir Ahi Evran University, Sciences Mechanical Engineering Department, 32200, Turkey \\ *Corresponding Author Email: eng456609@gmail.com ORCID: 0000-0002-5112-8261 \\ ${ }^{2}$ Kirsehir Ahi Evran University, Sciences Mechanical Engineering Department, 32200, Turkey \\ Email: m.danismaz@ ahievran.edu.tr ORCID:0000-0003-2077-9237 \\ ${ }^{3}$ Iraqi Radioactive Source Regulatory Authority (IRSRA), Baghdad \\ Email: faez_radiophysics@yahoo.com ORCID: 0000-0002-0003-0467
}

\section{Article Info:}

DOI: $10.22399 /$ ijcesen.1035440

Received : 11 December 2021

Accepted : 28 December 2021

\section{Keywords}

Energy

Nanotechnology

Radioactive waste

\begin{abstract}
:
Most world country dependent on foreign oil to make things working, which means political disputes or any disputes between countries can result in energy crunches. The negative changes that occur in the global climate and environment due to the burning of fossil fuels, stimulate the search for modern and environmentally friendly sources of energy production. In addition, continued concern about the storage and processing of nuclear waste may limit nuclear energy options. New concepts use nanotechnology as a new application for production of the electricity. In the modern thin-film application technologies, a number of layers can be deposited to improve the cells' energy density, reduce operating temperatures, and lower manufacturing costs. Solid oxide fuel cells (SOFCs), which have the ability to convert chemical energy into electrical energy without combustion, are among the advantages of this cell; High efficiency and much less pollution. Fuel cells - zinc, air, proton exchange membranes, and solid oxide are recent and established energy applications. Several of these solid oxide fuel cells (SOFCs) have emerged as fuel cell technology that has additional positive advantages.
\end{abstract}

\section{Introduction}

According to many previous studies, it can be considered that 20 percent of the electric power in most countries of the world is through nuclear power plants, but the sources of electric power relying on nuclear energy still have many problems and accidents, although their number is less, their impact is long-term. After the Chernobyl and Fukushima experiments and the spread of radioactive pollutants for many world counties, concerns continued to be a constant concern $[1,2]$. In the end and during the normal working operation the nuclear reactor, the radioactive waste and other kinds of side production disposal or storage to minimize the hazards of nuclear waste generated by nuclear reactors. In countries where electrical energy is produced from nuclear plants, very large amounts of radioactive spent fuel are temporarily stored from commercial nuclear plants. Most of the storage sites almost reach the total storage capacity. The establishment of permanent storage sites has many complex criteria for safety and environmental reasons. Radioactive Cesium (Cs-137) from the Chernobyl accident can still be detected in some soil models, in parts of central, eastern, and northern Europe, many animals, plants, and fungi near the accident site are still radioactive to the level that they may become unsafe for human consumption, Cesium has a half live about 30 years, it emits gamma radiation which it is harmful to live cells [3]. In figure 1 a picture from Chernobyl reactor after the explosion that happens in 1986 is displayed [4]. There are many studies that used nanotechnologies for the production of electricity, for example, an investigator team focus on Nanotechnology for catalysis and solar energy conversion focuses on the application of nanotechnology in addressing the current challenges of energy conversion [5]. Production the electricity by using crystalline silicon technologies for solar cell 
production [6]. Production electricity by using the chemical and thin-film deposition processes depending on some material to minimize radioactive waste and its long storage [7].

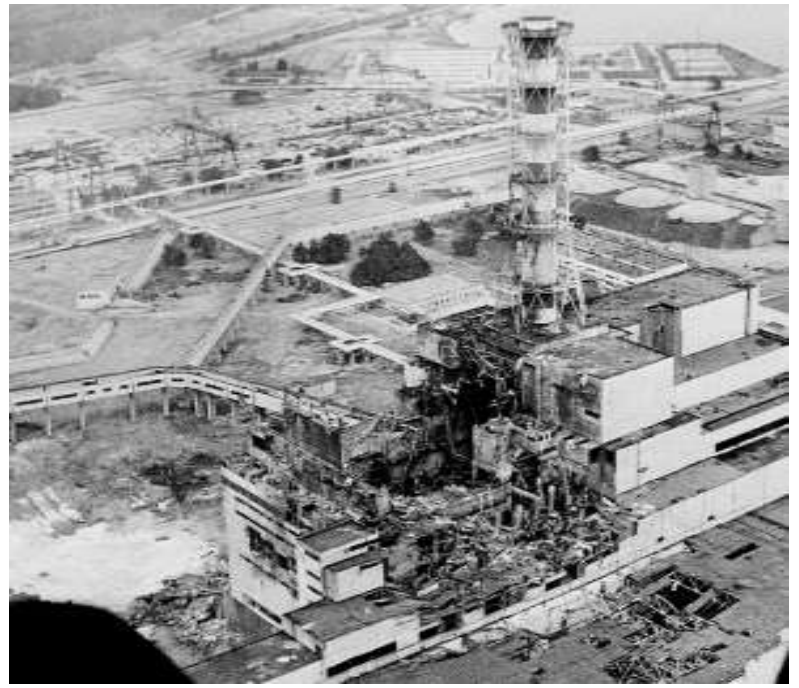

Figure 1. Chernobyl reactor after the explosion that happens in 1986 [4]

\section{Thin-Film Technologies}

There is a great demand for thin-film characterization techniques recently, due to the widespread proliferation of coating technology in many modern applications. The mechanical, functional, and engineering properties of thin films can vary greatly, making them difficult to characterize for general purposes. However, confocal microscopy and optical interferometry profiling can be considered among the few methods that can be used to characterize thin films [8]. It is possible to measure the thickness, residual pressure, adhesion, and roughness of different types of films using a thin-film application technique, this characterization technique can provide higher quality results than those of traditional characterization methods, such as indentation or scratch tests. For example, lenses in all modern optical systems, such as microscopes, binoculars, or eyeglasses, are covered with multilayer films that have different functions (optical, mechanical, or abrasion-resistant). The production of electric energy by burning fossil fuels changes the climate negatively due to the emission of greenhouse gases. These gases are emitted to the atmosphere and contribute negatively to global climate change.

\section{Combine Nanotechnology and Radioactive Waste to Generate Electricity}

Nowadays nanotechnology is getting more focuses attention and thus is building high expectations in

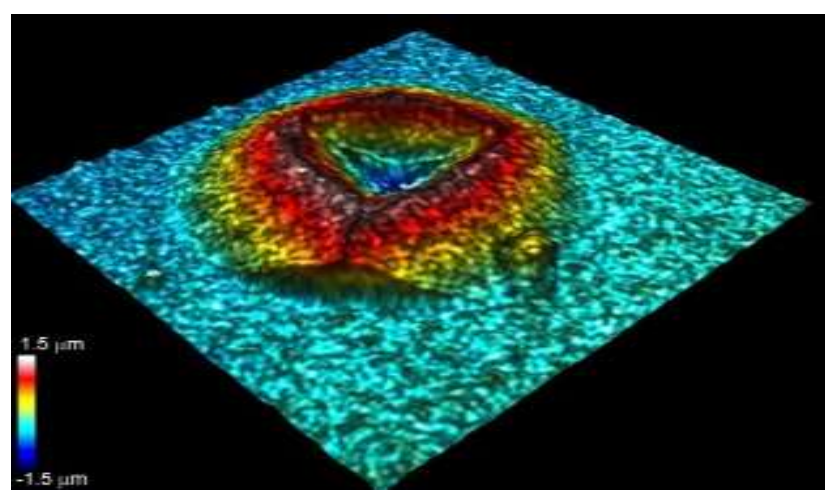

Figure 2. Production of tools and molds for machining, anticorrosive materials, materials for functional and decorative coatings [9].

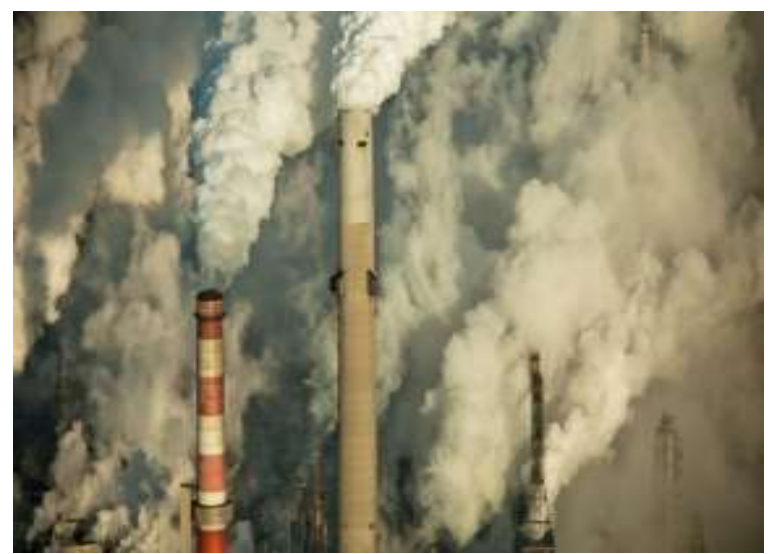

Figure 3. The ill effects of fossil fuels for infrastructure through toxic emissions into the atmosphere

many different community. Among them, great achievements are particularly needed in the energy sector which will allow us to maintain our growing appetite for energy. An example for thin-film technology is displayed in figure 2 [9]. For the case of fossil fuel effect, it is displayed in figure 3 to show the ill effects of fossil fuels for infrastructure through toxic emissions into the atmosphere. In figure 4 , the world population, energy and electricity demands is displayed [10]. It requires a way that includes the environment in the wealth production equation as we gather more evidence about the human impact on climate, biodiversity, air, water, and soil quality [10]. Therefore we can use this new technology application to promote anew electricity source in some special location by using radioactive waste material. By this application we get more benefit such as:-

a- Find alternative sources of energy Efficiency Clean power is needed. 
a- Degrease a large amount of radioactive waste material in the world.

b- Resolve one of important international human hazard.

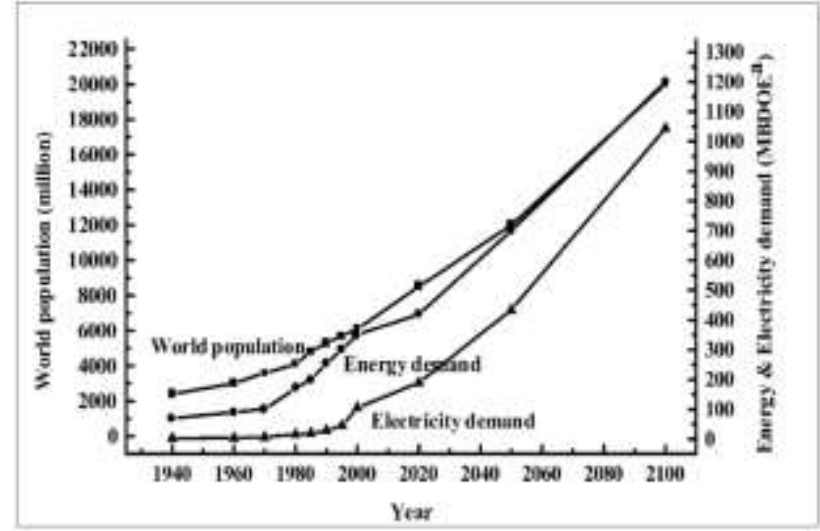

Figure 4. The world population, energy and electricity demands [10].

\section{Find Alternative Sources of Energy}

A fuel cell (Solid Oxide Fuel cell - SOFCs) is an energy conversion device that produces electricity by electrochemical combination of fuel and oxidizing materials through electrodes and an electrolyte that conducts ions. Quieter since there are no moving parts. A fuel cells are highly efficient and far less polluting. Typical Fuel Cell Configuration is displayed in figure 5 [11].

Production electricity by using the chemical and thinfilm deposition processes depending on some material to minimize radioactive waste and its long storage.

\subsection{Consists of Solid-oxide fuel cells (SOFCs)}

A fuel cell consists of three electrochemical components:

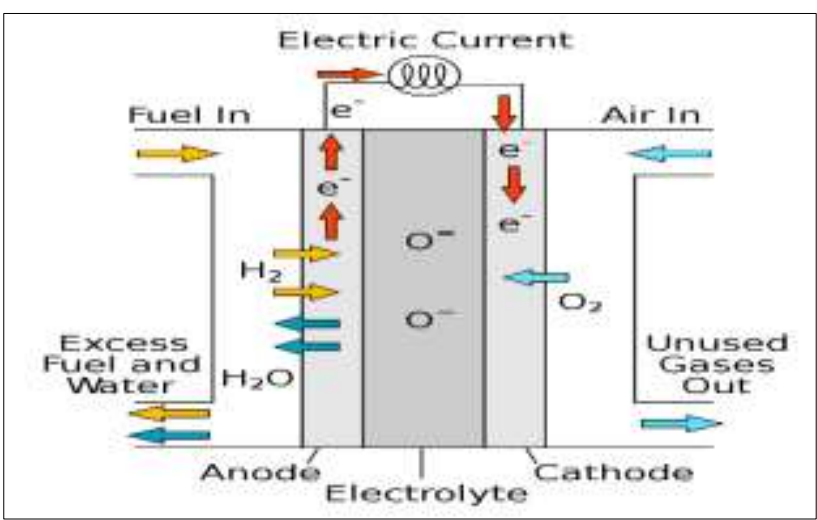

Figure 5. Typical Fuel Cell Configuration [11].
1- Cathode reduces oxygen from air.

2- An electrolyte that ensures the transport of oxygen ions.

3- Anode which oxidizes fuel (hydrogen or another combustible gas) by combining with the oxygen ions.

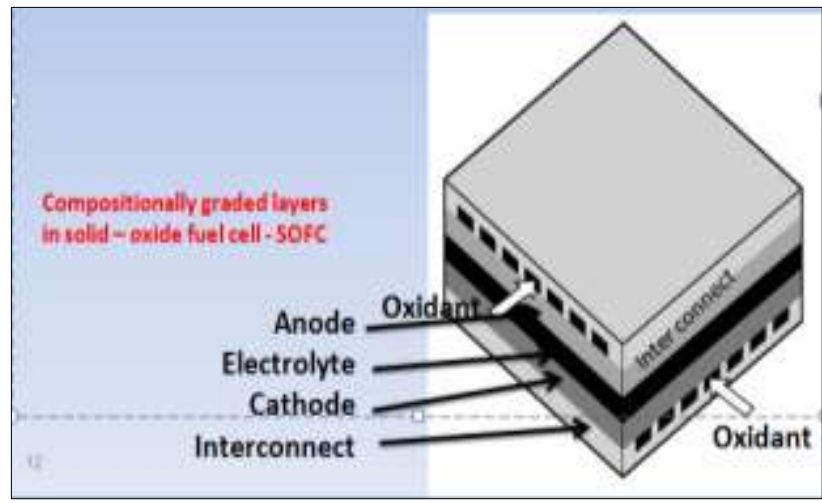

Figure 6. The graded layers in a solid-Oxide fuel cell (SOFC) [12].

A single fuel cell has the ability to generate a lower voltage (about 1 volt), the higher voltage being by connecting several fuel cells in series (a fuel cell stack). To further increase production efficiency and reduce resistance losses, it is necessary to reduce the thickness of its electrolyte layer. The development of fuel cells is carried out through the use of several methods, including the use of yttria-stable zirconia thin films to reduce the thickness of the electrolyte, in addition to making the operating temperatures of fuel cells at least 200 degrees Celsius. There are many studies and research to improve the thin-film technology used in SOFC fabrication and to increase the energy density, that the development of a new thin-film deposition technology that may pave the way for the commercialization of SOFCs. This technique is based on colloidal processing, in which the substrate is repeatedly dipped in a colloidal solution. This well-known process has been modified for a single coating ranging in thickness from 1 to 80 $\mu \mathrm{m}$. The new technique can be applied to a variety of substrate geometries. Cross section of yttriumstabilized zirconia electrolyte (photographed at various resolutions). Chemical deposition processes and improved thin films provide a strong coating for oxide materials. The coating of new complex and planar substrates should be in a variety of ways that will be particularly useful for applications requiring higher production efficiency. There are many manufacturing and laboratory in many countries work hardly to improve this new accept technologies, the result of these innovations, next-generation fuel cells are helping new and modern industries and special applications reduce manufacturing costs and thus accelerate commercialization of existing SOFC 
designs. The graded layers in a solid is displayed in figure 6 [12] and a SEM picture is shown in figure 7.

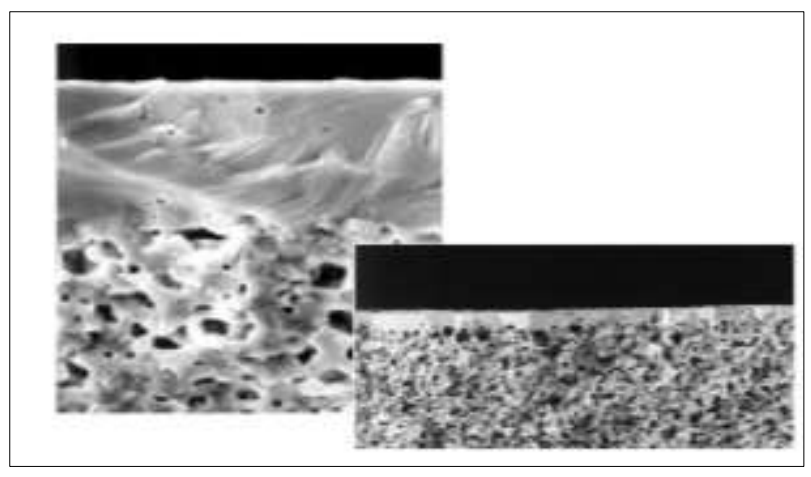

Figure 7. Thin film for use in a solid-oxide fuel cell (SOFC)

\section{Conclusions}

A wide spectrum of energy technologies will be needed to meet the long-term energy needs of the world. Therefore, it can use the new technology application in thin film characterization by using radioactive waste material to product energy. An electrical interconnect provides contact between cells by single coating in the ranges from 1 to 80 micrometers thickness. A fuel cell can be made more efficient when its electrolyte layer is made thinner, thus reducing its resistance losses. All these processing will increasing the carbon dioxide in the climate as it used to get and generate the energy to keep every things working. All these processing should be under controlling.

\section{Author Statements:}

- Ethical approval: The conducted research is not related to either human or animal use.

- Conflict of interest: The authors declare that they have no known competing financial interests or personal relationships that could have appeared to influence the work reported in this paper

- Acknowledgement: The authors declare that they have nobody or no-company to acknowledge.

- Author contributions: The authors declare that they have equal right on this paper.

- Funding information: The authors declare that there is no funding to be acknowledged.

- Data availability statement: The data that support the findings of this study are available on request from the corresponding author. The data are not publicly available due to privacy or ethical restrictions.

\section{References}

[1] Steinhauser, G., Brandl, A. and Johnson, T.E., (2014). Comparison of the Chernobyl and Fukushima nuclear accidents: a review of the environmental impacts. Science of the Total Environment, 470:800817. DOI: $10.1016 /$ j.scitotenv.2013.10.029.

[2] Friedman, S.M., (2011). Three Mile Island, Chernobyl, and Fukushima: An analysis of traditional and new media coverage of nuclear accidents and radiation. Bulletin of the Atomic Scientists, 67(5):5565. DOI: $10.1177 / 0096340211421587$

[3] Steinhauser, G., Brandl, A., \& Johnson, T. E. (2014). Comparison of the Chernobyl and Fukushima nuclear accidents: a review of the environmental impacts. Science of the total environment, 470, 800817.

[4] Itoh, M., (2018). Wildlife in the Exclusion Zone in Chernobyl. In Animals and the Fukushima Nuclear Disaster (pp. 177-187). Palgrave Macmillan, Cham.

[5] Banin, U., Waiskopf, N., Hammarström, L., Boschloo, G., Freitag, M., Johansson, E. M., \& Brudvig, G. W. (2020). Nanotechnology for catalysis and solar energy conversion. Nanotechnology, 32(4): 042003. DOI: 10.1088/1361-6528/abbce8

[6] Manna, T. K., \& Mahajan, S. M. (2007). Nanotechnology in the Development of Photovoltaic Cells. International Conference on Clean Electrical Power, pp. 379-386, doi: 10.1109/ICCEP.2007.384240.

[7] Boxwell, M. (2010). Solar electricity handbook: A simple, practical guide to solar energy-designing and installing photovoltaic solar electric systems. Greenstream publishing.

[8] Silverman, T.J., Jahn, U., Friesen, G., Pravettoni, M., Apolloni, M., Louwen, A. et al. (2014). Characterization of performance of thin-film photovoltaic technologies. IEA.

[9] Li, B., Gali, O.A., Shafiei, M., Hunter, J.A. and Riahi, A.R., (2016). Aluminum transfer buildup on PVD coated work rolls during thermomechanical processing. Surface and Coatings Technology, 308:244-255.

DOI: 10.1016/j.surfcoat.2016.07.091

[10] Serrano, E., Rus, G. and Garcia-Martinez, J., (2009). Nanotechnology for sustainable energy. Renewable and Sustainable Energy Reviews, 13(9):2373-2384. DOI: 10.1016/j.rser.2009.06.003

[11] Stambouli, A.B. and Traversa, E., (2002). Fuel cells, an alternative to standard sources of energy. Renewable and sustainable energy reviews, 6(3):295-304. DOI:10.1016/S1364-0321(01)00015-6

[12] Badwal, S.P.S., Giddey, S., Munnings, C. and Kulkarni, A., (2015). Review of progress in high temperature solid oxide fuel cells. Chem Inform, 46(31) DOI: 10.1002/chin.201531316 